\title{
OPTIMALISASI PENGEMBANGAN PRODUK OLAHAN SIWALAN DI DUSUN TENGGINA DESA BATANG-BATANG DAYA
}

\author{
Sucipto $^{1^{*}}$, Siti Nuurlaily Rukmana ${ }^{2}$, Titik Setyowati ${ }^{3}$ \\ ${ }^{1}$ Fakultas Ekonomi, Universitas Terbuka \\ ${ }^{2}$ Fakultas Teknik Sipil dan Perencanaan, Universitas PGRI Adi Buana Surabaya \\ ${ }^{3}$ Fakultas Ilmu Keguruan dan Pendidikan, Universitas Terbuka \\ Email: suciptosucipto@ecampus.ut.ac.id
}

\begin{abstract}
Informasi Artikel Abstrak
Kata kunci:

Produk

Pengelolaan,

Diversifikasi Produk.

Diterima: $30-12-2020$

Disetujui: 22-04-2021

Dipubikasikan: 14-07-

Dusun Tenggina merupakan yang secara administrasi masuk Desa BatangBatang Daya yang memilik potensi terbesar perkebunan siwalan. Keberadaan potensi tersebut tidak diimbangi dengan kemampuan/pengetahuan masyarakat dalam pengelolaan siwalayan mejadi beberapa produk yang memiliki nilai ekonomi tinggi dan kemampuan dalam menggunakan teknologi. Kegiatan pengabdian kepada masyarakat ini bertujuan untuk membantu masyarakat mampu mengolah siwalan menjadi beberapa produk dan masyarakat mampu mengemas produk yang memiliki nilai jual tinggi. Metode kegiatan dilakukan dengan cara sosialisasi, praktik pembuatan olahan dan monitoring pasca kegiatan. Hasil pelatihan dapat dirasakan oleh masyarakat bahwa sekitar $83 \%$ yang mengikuti pelatihan memiliki pemahaman dan mengetahui bahwa siwalan bisa dikembangkan menjadi beberapa produk. Untuk keterlibatan pemerintah lokal dan perguruan tinggi masih $0 \%$, sehingga untuk kedepannya diperlukan peran semua stakeholder untuk pengembangan pengelolaan pohon siwalan menjadi produk unggulan di Desa Batang-Batang Daya.
\end{abstract}

Keywords :

Siwalan Products,

Management, Product

Diversification

\footnotetext{
Abstract

Dusun Tenggina is administratively included in the Batang-Batang Daya Village which has the greatest potential for siwalan plantations. The existence of this potential is not balanced with the ability / knowledge of the community in managing siwalan into several products that have high economic value and the ability to use technology. This community service activity aims to help the community be able to process palm oil into several products and the community is able to package products that have a high selling value. The method of activity is carried out by means of socialization, processing practice and post-activity monitoring. The results of the training can be felt by the community that about $83 \%$ of those who attend the training have an understanding and know that siwalan can be developed into several products. For the involvement of the local government and universities is still $0 \%$, so in the future the role of all
} 
stakeholders is needed to develop the management of palm trees into a superior product in Batang-Batang Daya Village.

\section{PENDAHULUAN}

Dusun Tenggina merupakan salah satu wilayah yang memiliki potensi perkebunan siwalan di Desa Batang-Batand Daya Kabupaten Sumenep. Perkebunan menjadi salah satu program unggulan dengan tujuan untuk membuka dan meningkatkan kesempatan kerja serta pendapatan masyarakat atau petani lokal (Putrajaya, 2012).

Hasil kajian menunjukan bahwa pohon siwalan mulai dari daun, batang, buah, sampai tongkol bunganya bisa diolah menjadi produk. Misalnya, tongkol bunga siwalan jika disadap dapat menghasilkan nira atau dapat menjadi minuman legen (la'ang) (Kirana, Hastuti, \& Suarsini, 2016).

Fakta di lapangan bahwa luas perkebunan siwalan tidak diimbangi dengan tingginya produktivitas siwalan. Hal ini bisa dilihat pada tahun 2016-2017 mengalami peningkatan dari 743 menjadi 1.533 sedangkan untuk produk siwalan mengalami penuruan dari 3.715 menjadi 213 (Kecamatan Dalam Angka, 2017 (BPS, 2016) (BPS, 2017).)

Persoalan di atas disebabkan oleh dua faktor yaitu, pertama, rendahnya pengetahuan masyarak mengenai pengolahan siwalan menjadi beberapa produk (Kirana et al., 2016). Kedua, terbatasnya penggunaan teknologi dalam pengelolaan siwalan.

Kreativitas dan inovasi pengolahan siwalan menjadi beberapa produk tersebut harus diterapkan ditingkat masyarakat khususnya Desa Batang-batang Daya dan masyarakat yang mempunyai pohon siwalan serta memproduksinya. Ciri khas masyarakat desa dalam menerima suatu masukan teknologi baru masyarakat menghendaki bukti yang nyata dan informasi secara komprehensif. Untuk mengatasi hal tersebut maka diperlukan kerjasama kemitraan antara perguruan tinggi melalui akademisi dan masyarakat lokal tersebut.

Cara yang paling tepat untuk mewujudkan hal tersebut dan memformulasikan bentuk kemitraan dengan menyelenggarakan pelatihan pembuatan sirup, nata de siwalan dan wedang legen. Harapan dalam kegiatan pengabdian masyarakat ini dapat meningkatkan pengetahuan dan pendapatan masyarakat khususnya di Desa Batang-batang Daya Kecamatan Batang-batang Kabupaten Sumenep.

\section{METODE}

Kegiatan pengabdian kepada maysarakat ini dilakukan di Dusun Tenggina RT. 02/RW.11 Desa Batang-Batang Daya Kecamatan Batang-Batang Kabupaten Sumenep (Gambar 2). Sasaran kegiatan ini adalah masyarakat dan Kelompok Usaha Bersama "Rumput Gajah" di Dusun Tenggina Desa Batang-Batang Daya. 
Berdasarkan permasalahan mitra maka metode pendekatan yang dilakukan untuk memberi sololusi yaitu, sosialisasi potensi pengelolaan siwalan menjadi beberapa produk bernilai ekonomi tinggi, pengemasan dan teknik penjualan baik secara offline dan online. Selain itu juga, penentuan harga dari setiap produk. Metode ini dinilai langkah awal dalam peningkatan wawasan masyarakat (Latifatul, A, A, \& Nur, 2018).

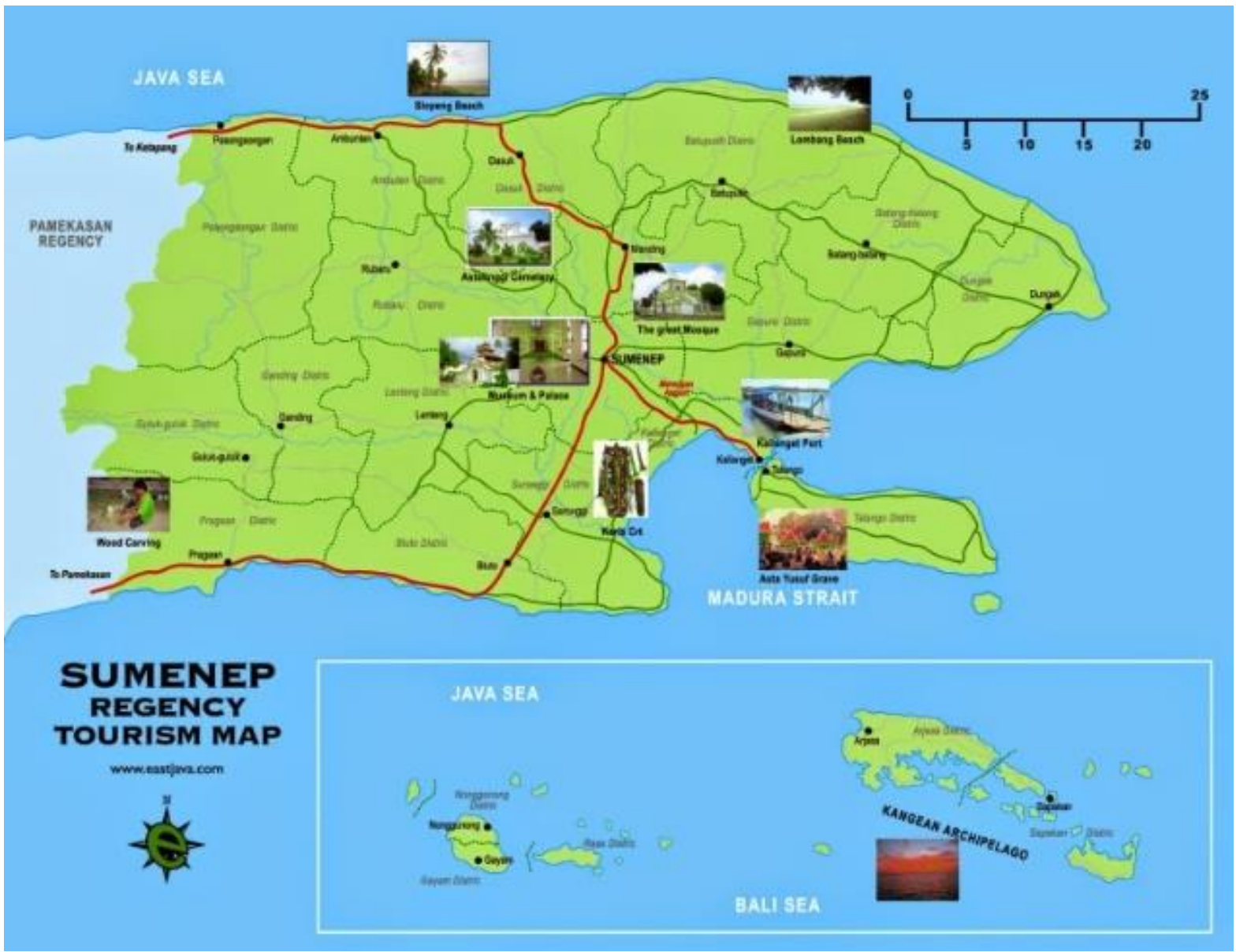

Gambar 1. Peta Administrasi Kabupaten Sumenep

Pelaksanaan program pengabdian kepada masyarakat pada bulan Oktober-November 2020. Adapun tahapan pelaksanan kegiatan pengabdian kepada maysarakat sebagai berikut:

a. Observasi ke lapangan

Survie lokasi dilakukan oleh tim PKM Universitas Terbuka. Hasil survie menunjukan bahwa Dusun Tenggina memiliki potensi siwalan yang sangat berlimpah. Namun, selama ini masyarakat hanya bisa membuat gula, tangguli (semacam sirup). Hal tersebut disesbabkan oleh kemampuan dan pengetahuan masyarakat lokal untuk membuat produk olahan siwalan masih terbatas. Oleh karena itu itu tim PKM dosen Universitas Terbuak memutuskan untuk mengadakan sosialisasi tentang bagaimana membuat olahan pohon siwalan menjadi beberapa produk.

b. Melakukan identifikasi permasalahan apa saja yang dialami oleh masyarakat mulai dari produksi, pengemasan, penentuan harga dan penjualan. 
c. Sebelum melaksanakan kegiatan sosialisasi, penyuluhan dan pelatihan di Dusun Tenggina tim PKM Universitas Terbuka melakukan uji coba produk terlebih dahulu. Kegiatan uji coba produk ini bekerjasama dengan Jurusan Tataboga Universitas PGRI Adi Buana Surabaya. Tujuan uji coba untuk memastikan produk layak untuk dikonsumsi dan memiliki nilai jual. Uji coba yang dilakukan yaitu, pembuatan jelly kering dan basah, pembuatab wedang legen, pembuatan sirup.

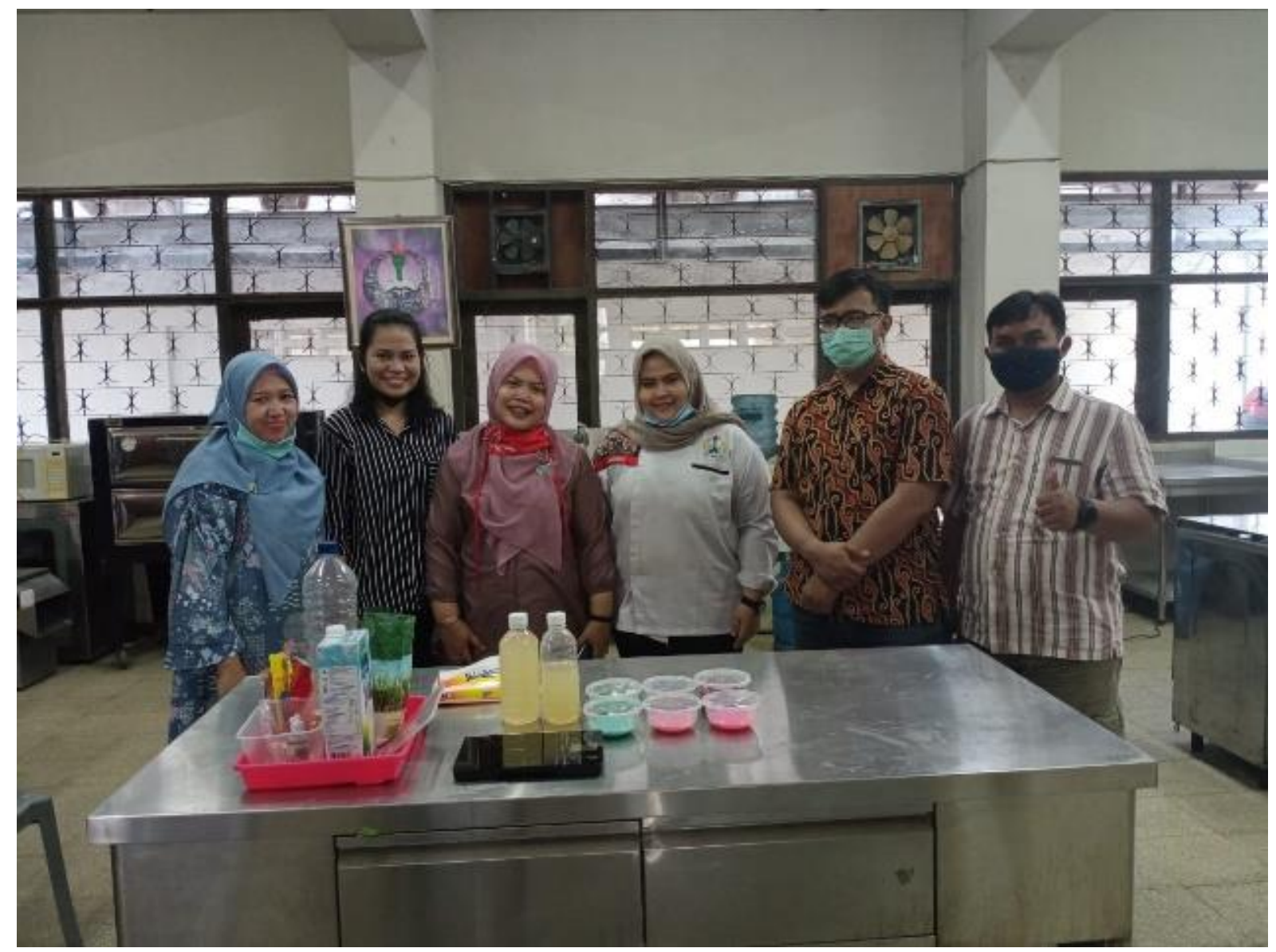

Gambar 2. Foto Uji Coba Produk di Lab. Tataboga Universitas PGRI Adi Buana Surabaya

d. Persiapan alat-alat dan bahan untuk pembuatan olahan siwalan. Bahan utama yang disiapkan dalam kegiatan sosialisasi pengolahan produk siwalan antara lain sebagai berikut:

1. Susu full cream

2. Tepung agar-agar

3. Gelatin

4. Nutrijell

5. Pewarna Pengan

6. Gula Pasir

7. Legen

8. Siwalan

9. Sere 
10. Jahe

11. Kayu Manis

12. Timbangan

13. Cetakan untuk jelly

14. Botol+tutup botol (untuk minuman wedang legen dan sirup)

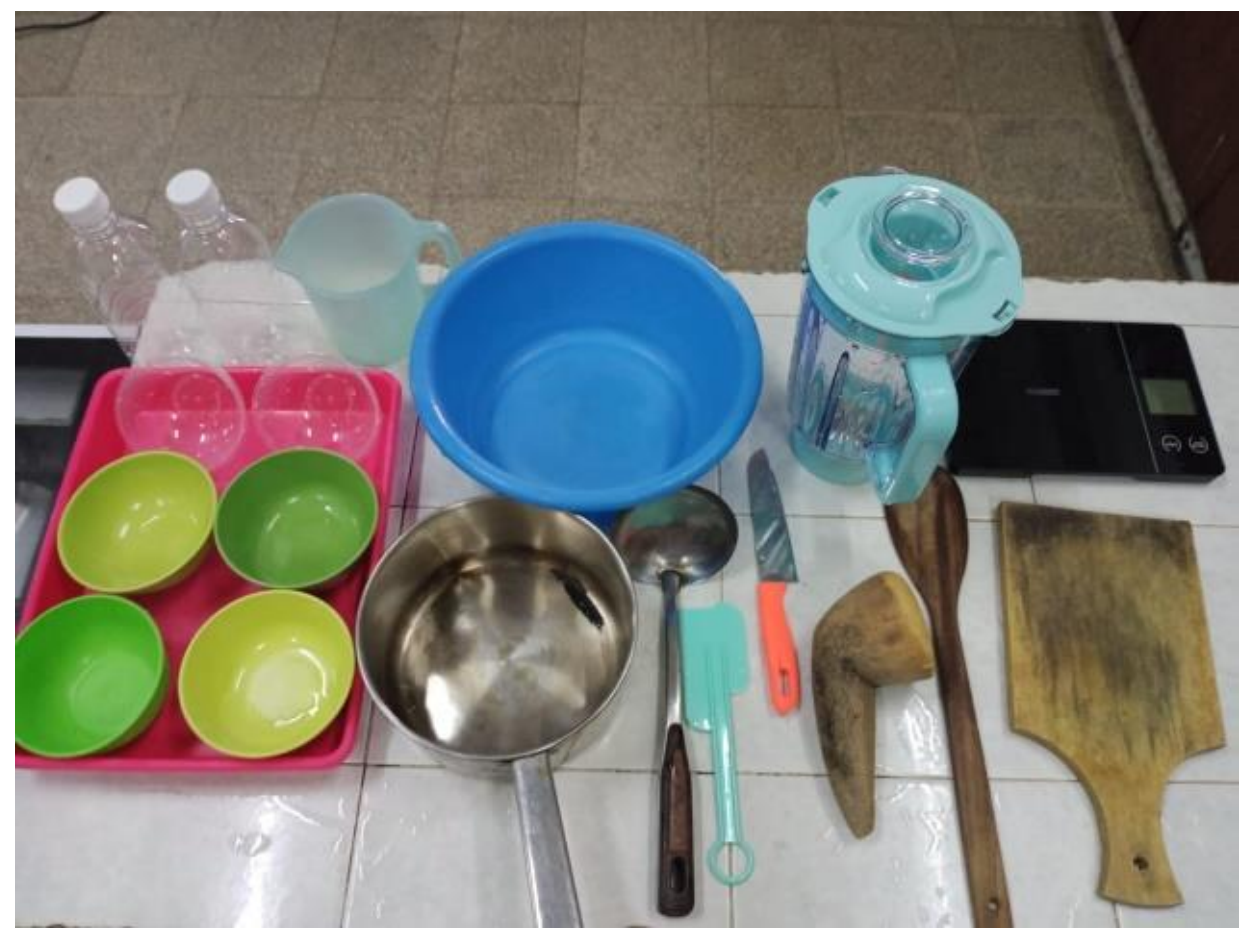

Gambar 3. Foto Peralatan yang digunakan

e. Pelaksanaan Sosialisasi potensi pengelolaan siwalan

f. Pelatihan pembuatan olahan siwalan

g. Melakukan evaluasi dan monitoring kepada masyarakat untuk mengetahui sejauh mana pemahaman masyarakat dan untuk melihat kualitas hasil dan pengembangan produk utamanya dalam penjualan.

\section{HASIL DAN PEMBAHASAN}

\section{a. Pelaksanaan Program PKM}

Kondisi Awal

Pengelolaan siwalan hanya fokus pada pembuatan gula dan tangguli. Masyarakat masih belum tahu banyak bahwasanya siwalan bisa dikembangkan menjadi beberapa produk yang memiliki nilai ekonomi tinggi. Melihat konidisi tersebut tim pelaksana PKM Universitas Terbuka Surabaya menawarkan adanya kegiatan pengelolaan siwalan menjadi beberapa produk dan sekaligus 
pengemasannya. Masyarakat semakin tertarik setelah megnetahui bahwa siwalan bisa dikembangkan menjadi beberapa produk.

\section{Kondisi Akhir}

Setelah diadakan pelatihan produk, maka dapat dukungan dari tim PKK Desa Batang-Batang Daya untuk dijadikan sebagai produk unggulan UKM Desa. Dan siap membantu memproposikan terutama ketika ada acara di tingkat kecamatan.

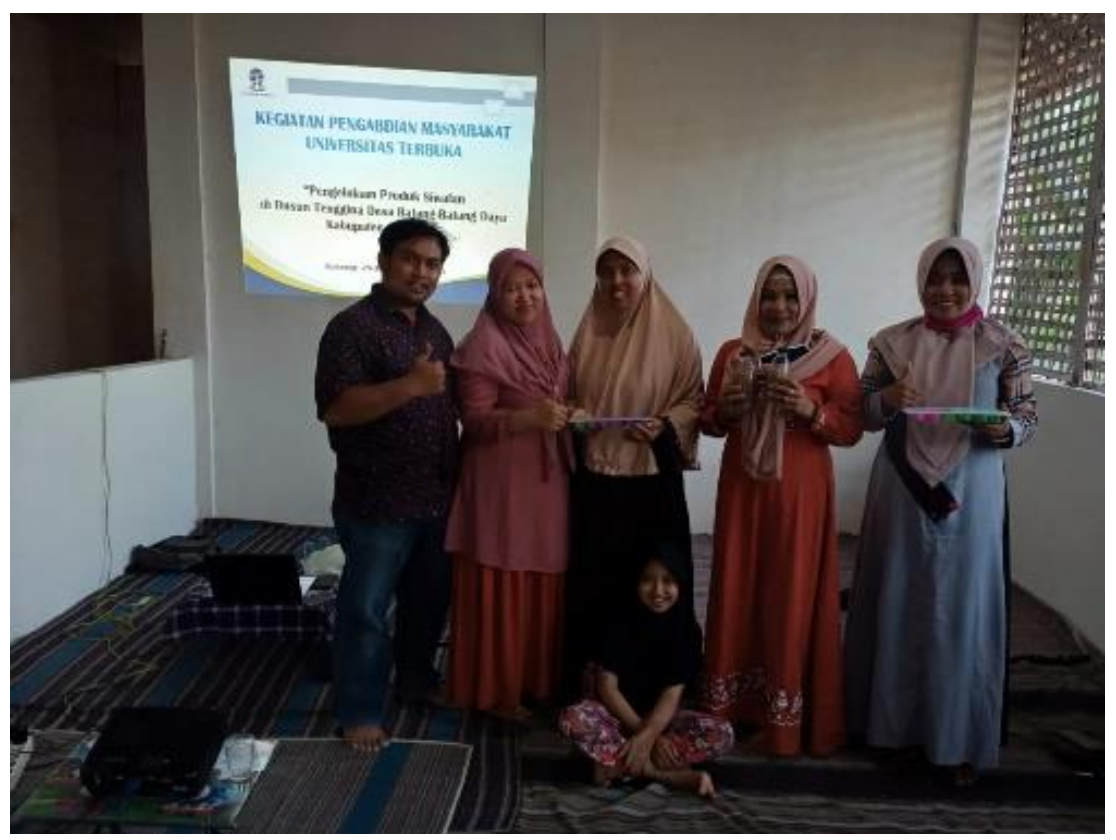

Gambar 4. Foto bersama Wakil Ketua PKK, Pokja dan Pengurus Kelompok Usaha Bersama

"Rumput Gajah"

\section{b. Pemahaman Masyarakat Mengenai Pengelolaan Produk Siwalan}

Pelatihan pengelolaan pohon siwalan memberikan dampak terhadap meningkatnya pengetahuan masyarakat. Hal ini ditunjukan dengan data $83 \%$ masyarakat yang mengikut pelatihan memiliki pemahan dan mengetahui bahwa pohon siwalan bisa dikembangkan menjadi beberapa produk dan memiliki nilai ekonomi tinggi.

Untuk menjaga keberlanjutan ekonomi lokal dengan memanfaatkan sumber daya yang ada maka diperlukan keterlibatan pemerintah desa dan pihak-pihak yang lain dalam hal ini adala perguruan tinggi. Selama ini pemerintah dan perguruan tinggi atau bahkan pihak yang lain masih belum pernah memberikan sentuhan dalam program untuk pengembangan pengelolaan pohon wisalan terhadap masyarakat Dusun Tenggina Desa Batang-Batang Daya. Berdasarkan kuesioner yang diberikan kepada peserta pelatihan bahwa peran pemerintah lokal dan perguruan tinggi masih 0\% keterlibatannya. Sehingga untuk kedepannya diperlukan peran semua stakeholder untuk pengembangan pengelolaan pohon siwalan. 


\section{KESIMPULAN}

Hasil pelatihan dapat dirasakan oleh masyarakat bahwa sekitar $83 \%$ yang mengikuti pelatihan memiliki pemahaman dan mengetahui bahwa siwalan bisa dikembangkan menjadi beberapa produk. Untuk keterlibatan pemerintah lokal dan perguruan tinggi masih $0 \%$, sehingga untuk kedepannya diperlukan peran semua stakeholder untuk pengembangan pengelolaan pohon siwalan menjadi produk unggulan di Desa Batang-Batang Daya.

\section{UCAPAN TERIMAKASIH}

Penulis mengucapkan terima kasih kepada Universitas Terbuka yang telah memberi dukungan financial terhadap pengabdian ini. Dan terimakasih juga kepada mitra Kelompok Usaha Bersama "Rumput Gajah" yang telah bersedia menjadi tempat kegiatan Pengabdian ini.

\section{DAFTAR PUSTAKA}

Anonymous. (2018). Peta Kabupaten Sumenep. Retrieved August 20, 2018, from http://www.eastjava.com/tourism/sumenep/map/sumenep-map.png

BPS. (2016). Katalog BPS : 1101002.3529180 Kecamatan Batang Batang Dalam Angka 2016 Badan Pusat Statistik Kabupaten Sumenep. Sumenep. http://doi.org/10.15713/ins.mmj.3

BPS. (2017). Katalog BPS : 1101002.3529180 Kecamatan Batang - Batang Dalam Angka 2017 Badan Pusat Statistik Kabupaten Sumenep. Sumenep. http://doi.org/10.15713/ins.mmj.3\

Kirana, C., Hastuti, U. S., \& Suarsini, E. (2016). Kajian Kualitas Nata de Nira Siwalan (Borassus Flabelliver L) dengan Variasi Macam Gula dalam Beberapa Konsentrasi sebagai Materi Handout Biologi Kelas XII MAN Pamekasan. In Proceeding Biology Education Conference (ISSN : 2528 - 5742) (Vol. 13, pp. 178-186). Solo: Universitas Sebelas Maret Solo. Retrieved from https://jurnal.uns.ac.id/prosbi/article/viewFile/5688/5056

Latifatul, F. N., A, A., A, A., \& Nur, K. R. M. (2018). Pengaruh Sosialisasi Pemilahan Sampah Organik Dan Non Organik Serta Manajemen Sampah Terhadap Penurunan Volume Sampah Di Dusun Krajan Desa Kemuningsari Lor Kecamatan Panti Kabupaten Jember. The Indonesian Journal of Health Science, (September), 84. https://doi.org/10.32528/ijhs.v0i0.1529

Putrajaya. (2012). PROFIL DAN POTENSI KABUPATEN SUMENEP. Retrieved August 17, 2018, from http://kim-putrajaya-dasuk.blogspot.com/2012/02/profil-dan-potensi-kabupatensumenep.html 